\title{
PENERAPAN FRAMEWORK YII PADA PEMBANGUNAN SISTEM PPDB SMP BPPI BALEENDAH KABUPATEN BANDUNG
}

\author{
Johni S Pasaribu \\ Teknik Informatika \\ Politeknik Piksi Ganesha \\ J1. Jend Gatot Subroto 301 Bandung 40274 \\ Email: johni_0106@yahoo.com
}

\begin{abstract}
Abstrak
Penerimaan peserta didik baru (PPDB) merupakan salah satu proses yang ada di instansi pendidikan seperti sekolah yang berguna untuk menyaring calon siswa yang terpilih sesuai kriteria yang ditentukan oleh sekolah tersebut untuk menjadi siswa didiknya. Pada umumnya proses PPDB dilakukan melalui tahapan pendaftaran, tes seleksi, dan pengumuman penerimaan siswa. Dalam penelitian ini penerapannya pada SMP BPPI Baleendah yang selama ini dilakukan secara manual atau sudah terkomputerisasi tetapi menggunakan Microsoft Office Excel. Pendaftaran secara manual masih menggunakan formulir yang menimbulkan antrian. Formulir pendaftaran tersebut akan dimasukkan oleh komite PPDB ke dalam komputer. Dengan semakin banyaknya calon siswa baru, maka proses memasukkan, mengolah dan memberikan informasi hasil PPDB memerlukan waktu.

Hasil yang diharapkan dari penelitian ini adalah menghasilkan sistem PPDB berbasis web menggunakan pendekatan YII Framework dengan metoda MVC (Model View Controller) pada SMP BPPI Baleendah yang dapat menyelesaikan masalah yang ada. Manfaat dari penelitian ini adalah memberikan kemudahan bagi admin maupun siswa itu sendiri. Langkah-langkah pengembangan sistem ini adalah studi pustaka, observasi, wawancara, analisis, perancangan, uji coba dan implementasi. Kesimpulan hasil dari penelitian ini adalah diharapkan dapat terbangunnya sistem informasi penerimaan siswa baru yang berbasis web.
\end{abstract}

Kata kunci : Perangkat Lunak, Penerimaan Peserta Didik Baru, Berbasis Web
The admission of new students is one of processes within educational institutions like school which is used to select candidate according to stated criteria by related school. Generally, the process of acceptance of new students began with registration, selection, and announcement steps of new student. This research was taken place at Junior High School (SMP) BPPI Baleendah which during the time has practiced the admission of new students manually or computerized but used Microsoft Office Excel only. The manual registration that are still using the form that led to long queues. The registration form hereinafter be recapitulated in the ledger by the committee PPDB into the computer. Because the number of applicants who pretty much and continues to grow, so that the input process, data processing and delivery of information resulting from the admission requires substantial time.

The expected outcome of this research is to produce PPDB system web-based using YII Framework with MVC method on SMP BPPI Baleendah which can solve problem. The benefit of this research is to provide an ease for administrator and student. The steps of development system are literature study, observation, interview, analysis, schematization, trial, and implementation as its method. The conclusion from research result hopes installed an information system of new student acceptance in web-based. The author suggested that these applications can grow more, as in the use of Mobile-based or Website.

Keywords: Software, Admission of New Students, Web Based

\section{Abstract}




\section{Pendahuluan}

Dengan perkembangan teknologi saat ini kebutuhan terhadap informasi sangat penting sehingga informasi harus dapat diakses kapan saja dan dimana saja dan tentu telah mengalami perkembangan yang pesat. Hampir semua kegiatan yang dilakukan oleh manusia pada jaman sekarang tidak luput dari campur tangannya sebuah teknologi berbasis Online dan tentunya sudah praktis serta terkomputerisasi. Dengan adanya kepraktisan dan komputerisasi ini dapat mempermudah dalam segala pekerjaan khususnya segala pendaftaran dan pengolahan datanya membutuhkan kecepatan, ketepatan atau kevalidan data. Salah satu yang dapat dirasakan oleh dampak dari kepraktisan dan terkomputerisasi ini yaitu di bidang pendidikan tepatnya di bagian administrasi sekolah yaitu pada kegiatan Penerimaan Peserta Didik Baru (PPDB).

Sekolah Menengah Pertama (SMP) BPPI Baleendah belum menerapkan sistem pendaftaran calon siswa-sisiwi baru maka dari itu dengan analisa yang sudah ada dibuatlah suatu sistem yang dapat menunjang produktivitas sekolah dalam meningkatkan pendidikan yaitu perangkat lunak pendaftaran siswa baru secara online menggunakan fasililtas internet. Melihat pentingnya peranan teknologi dalam mengatasi minimnya pendidikan maka diperlukan suatu rekayasa perangkat lunak untuk rekrutmen pendaftaran calon siswa baru agar sekolah bisa memperoleh keuntungan kompetitif di dunia pendidikan. Suatu perangkat lunak yang ditangani oleh komputer akan terasa lebih canggih, lebih pintar, lebih otomatis, lebih praktis, lebih efisien, lebih aman, lebih teliti dan lain sebagainya dibandingkan jika ditangani secara tradisional. Oleh karena itu atas dasar permasalahan-permasalahan diatas maka akan dibangun sebuah perangkat lunak pendaftaran calon siswa baru berbasis web menggunakan PHP dan MYSQL sebagai databasenya.

\section{Tinjauan Pustaka}

\section{II.1 Pengertian Penerimaan Peserta Didik Baru (PPDB)}

Penerimaan peserta didik baru pada dasarnya untuk memperlancar dan mempermudah dalam proses pendaftaran siswa-siswi baru, pendataan dan pembagian kelas seorang siswa-siswi. Sehingga dapat terorganisir, teratur dengan cepat dan tepat dengan beberapa persyaratan yang telah ditentukan oleh sekolah. Proses penerimaan peserta didik baru baru merupakan salah satu kewajiban pihak sekolah dan Dinas Pendidikan setiap tahun ajaran baru. Pada proses PPDB biasanya terdapat proses seleksi administrasi dan akademis calon siswa untuk memasuki jenjang pendidikan setingkat lebih tinggi.

\section{II.2 Pengertian Perangkat Lunak Aplikasi}

Suatu subkelas perangkat lunak komputer yang memanfaatkan kemampuan komputer langsung untuk melakukan suatu tugas yang diinginkan pengguna. Biasanya dibandingkan dengan perangkat lunak sistem yang mengintegrasikan berbagai kemampuan komputer, tapi tidak secara langsung menerapkan kemampuan tersebut untuk mengerjakan suatu tugas yang menguntungkan pengguna. Contoh utama perangkat lunak aplikasi adalah pengolah kata, lembar kerja, dan pemutar media.

Beberapa aplikasi yang digabung bersama menjadi suatu paket kadang disebut sebagai suatu paket atau suite aplikasi (application suite). Contohnya adalah Microsoft Office dan OpenOffice.org, yang menggabungkan suatu aplikasi pengolah kata, lembar kerja, serta beberapa aplikasi lainnya. Aplikasi-aplikasi dalam suatu paket biasanya memiliki antarmuka pengguna yang memiliki kesamaan sehingga memudahkan pengguna untuk mempelajari dan menggunakan tiap aplikasi. Sering kali, mereka memiliki kemampuan untuk saling berinteraksi satu sama lain sehingga menguntungkan pengguna. Contohnya, suatu lembar kerja dapat dibenamkan suatu dokumen pengolah kata walaupun dibuat pada aplikasi lembar kerja yang terpisah. (Wikipedia bahasa Indonesia).

\section{II.3 Kerangka Kerja (Framework) Pengembangan Aplikasi Web}

PHP adalah bahasa pemrograman server-side yang didesain spesifik untuk pengembangan aplikasi berbasis web. Banyak kelebihan dari bahasa pemrograman PHP, antara lain pada aspek performa, skalabilitas, portabilitas, open source, dan terutama untuk terkoneksi dan melakukan manipulasi terhadap sebuah basis data (Supaartagorn, 2011). Manajemen basis data dilakukan dengan Structure Query Language (SQL). Beberapa studi menyatakan bahwa bahasa query database tradisional tidak mudah digunakan untuk pengguna teknologi basis data yang tidak berpengalaman, sebagai konsekuensi karena interaksinya berbasis bahasa tekstual, seperti SQL (Avensano et al., 2002). 
Kerangka kerja perangkat lunak (software framework) adalah desain dasar yang dapat digunakan dan dikembangkan kembali untuk sebuah sistem atau subsistem aplikasi. Sebuah software framework menyediakan kumpulan kode dasar yang dapat membantu dalam proses pengembangan dan penggabungan komponen yang berbeda pada sebuah perangkat lunak (Paikens \& Arnicans, 2008). Sebuah kerangka kerja pemrograman dapat menyederhanakan proses menyusun kode fungsi program dengan mengurangi kode operasi-operasi yang bersifat repetitive (Upton, 2007). Karena tujuan framework adalah membantu melakukan aktivitas umum, banyak framework menyediakan pustaka (library) untuk akses database, manajemen data sesi, dsb (DocForge, 2010). Kerangka kerja pemrograman web berbasis bahasa pemrograman PHP-Hypertext Preprocessor memudahkan proses pengembangan aplikasi, membantu menyusun fungsi-fungsi sebuah sistem dengan waktu lebih cepat karena tidak harus menulisnya dari awal. Ini juga dapat meningkatkan kualitas dan stabilitas susunan kode pemrograman (Yicheng, 2011). Framework secara signifikan mengurangi waktu, sumber daya, usaha, yang dibutuhkan untuk mengembangkan dan mengelola aplikasi web. Selain itu, framework adalah arsitektur terbuka yang berbasis standard umum yang digunakan (Shan \& Hua, 2006).

Dalam desain sistem (design pattern), dikenal dengan baik salah satunya pendekatan Model-ViewController (Buschmann, 1996), yang dapat membuat mudah dalam proses pengembangan dan mengelola sebuah aplikasi, karena (Leff \& Rayfield, 2001): (1) tampilan (output) aplikasi dapat berubah drastis tanpa merubah struktur data dan business logic, (2) aplikasi dapat dengan mudah dikelola/digunakan dengan antarmuka (interfaces) yang berbeda-beda, misal adalah multi bahasa, atau pengaturan hak akses user yang berbeda-beda.

Pendekatan Model-View-Controller design
pattern adalah cara yang mudah untuk
mengembangkan arsitektur sistem perangkat lunak
interaktif (Krasner \& Pope, 1988). Dikenal juga
sebagai Presentation/Abstraction/Control (PAC)
design pattern, gagasan utamanya adalah untuk
memisahkan antarmuka dan data dibawahnya
(Coutaz, 1987). Pola Model-View-Controller terbukti

efektif untuk menciptakan dan mengorganisir aplikasi modular (Hofmeister, Nord, \& Soni, 2000).

\section{II.4 Pengertian YII Framework}

Yii adalah kerangka kerja PHP berbasis komponen dengan performansi tinggi untuk pengembangan aplikasi Web berskala besar. Ia menyediakan reusabilitas maksimum dalam pemrograman Web dan bisa mengakselerasi proses pengembangan secara signifikan. Nama Yii (dieja sebagai /i:/) singkatan dari easy, efficient dan extensible (mudah, efisien, dan bisa diperluas).

Framework Yii sendiri adalah framework yang memiliki konsep penyelesaian suatu masalah tidak lagi dilihat dari bagaimana prosedurnya, tetapi dari objek-objek apa saja yang terkait untuk melakukan penyelesaian masalah tersebut (Nugroho, 2010). Framework Yii mengimplementasi pola desain model-view-controller (MVC) yang diadopsi secara luas dalam pemrograman web. MVC bertujuan untuk memisahkan logika bisnis dari pertimbangan antar muka pengguna agar para pengembang bisa lebih mudah mengubah setiap bagian tanpa mempengaruhi yang lain (Sharive, 2013).

Yii mengimplementasikan pola desain modelview-controller $(M V C)$, yang diadopsi secara luas dalam pemrograman Web. MVC bertujuan untuk memisahkan logika bisnis dari pertimbangan antarmuka pengguna agar para pengembang bisa lebih mudah mengubah setiap bagian tanpa mempengaruhi yang lain. Dalam MVC, model menggambarkan informasi (data) dan aturan bisnis; view (tampilan) berisi elemen antar muka pengguna seperti teks, input form; sementara controller mengatur komunikasi antar model dan view.

Selain implementasi MVC, Yii juga memperkenalkan front-controller (controller depan), yang disebut Application, yang mengenkapsulasi konteks eksekusi untuk memproses sebuah request. Application mengumpulkan beberapa informasi mengenai request pengguna dan kemudian mengirimnya ke controller yang sesuai untuk penanganan selanjutnya.

Diagram berikut memperlihatkan struktur statis sebuah aplikasi Yii menurut website resmi Yii Framework: 


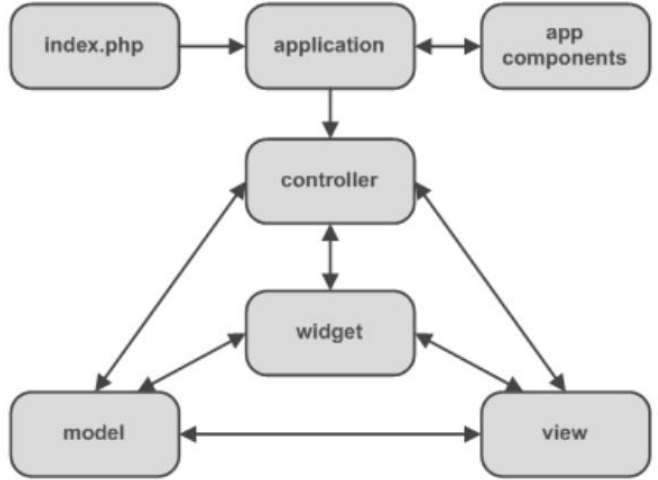

Gambar 1. Struktur statis aplikasi Yii (Sharive, 2013).

Yii Framework selalu menduduki peringkat pertama dalam beberapa tahun terakhir ini. Hal ini menunjukkan keunggulan Yii Framework, baik dalam segi kelengkapan, fitur, keamanan, dan paling penting adalah berkinerja tinggi serta kecepatannya yang jauh mengungguli Framework PHP lainnya.

Berikut adalah beberapa keunggulan dari Yii framework. Pertama, Yii adalah framework yang menggunakan PDO (PHP Data Object) yaitu untuk melakukan pengaksesan database pada PHP. PDO bekerja dengan membuat sebuah abstraksi akses database sehingga sebagai programmer tidak perlu terlalu jauh memikirkan kompatibilitas antar database.

Kedua, Yii adalah framework yang sepenuhnya OOP, dimana dengan OOP ini akan lebih baik dalam manage code, dapat mengelompokkan fungsi-fungsi ke dalam kelas-kelas, dapat modify program dengan lebih baik sehingga program dapat lebih rapi dan lebih mudah dibaca. Ketiga, Yii menggunakan model MVC (model view controller), dengan MVC dapat lebih terstruktur dalam membuat aplikasi, tidak perlu membuat banyak file pada root directory aplikasi. Keempat, Yii mempunyai lisensi BSD. Lisensi BSD tidak mengharuskan untuk deliver source code aplikasi. Kelima, Yii mempunyai code generator (Gii). Ini adalah salah satu tool yang sangat membantu kecepatan pengembangan aplikasi. Tool Gii ini dapat generate code untuk kemudian dimodifikasi. Dan yang keenam, Yii mempunyai komponen untuk pengecekan input yang terintegrasi. Ini merupakan fitur yang sangat berguna untuk keamanan.

\section{II.5 Pengertian Konsep MVC Pada Web}

Model-View-Controller (MVC) adalah pola arsitektur yang memisahkan aplikasi dalam tiga komponen utama Logis: Model, View dan Controller. Masing-masing komponen ini dibangun untuk menangani aspek-aspek tertentu pembangunan aplikasi. MVC adalah salah satu kerangka pembangunan web standar industri paling sering digunakan untuk menciptakan proyek yang terukur yang besar dan extensible.

Istilah MVC ini semakin familiar seiring dengan perkembangan framework PHP seperti Yii, Codeigniter, Laravel dan lain - lain. Hampir seluruh framework PHP ini menggunakan konsep MVC. Selain framework PHP konsep MVC juga digunakan pada CMS atau Content Management System seperti joomla, wordpress, elgg, prestashop dan lainnya.

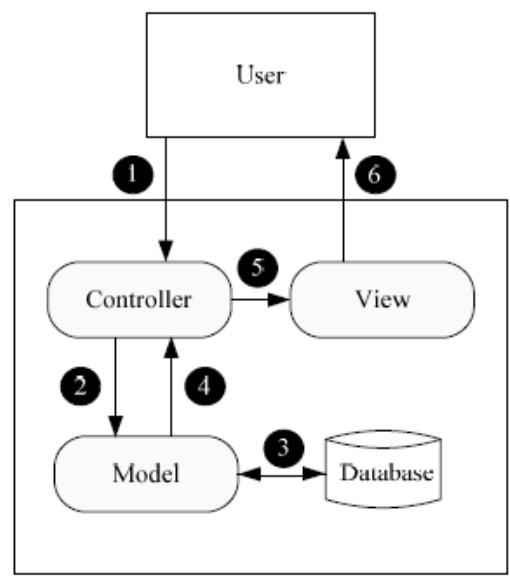

Gambar 2. Skema Model-View-Controller (MVC)

Pengertian MVC adalah sebuah bentuk pemrograman yang memisahkan berdasarkan logika penanganan tampilan, logika pengontrolan dan logika model. MVC bertujuan supaya pada pengembangan perangkat lunak yang besar mudah untuk dilakukan maintenance.

\section{Bagian - bagian dari MVC adalah:}

\section{Model}

Model adalah bagian kode program yang menangani query atau database. Jadi isi dari model merupakan bagian (fungsi-fungsi) yang berhubungan langsung dengan database untuk memanipulasi data seperti memasukkan data, pembaruan data, hapus 
data, dan lain-lain, namun tidak dapat berhubungan langsung dengan bagian view.

\section{View}

View adalah bagian kode prgram yang mengatur tampilan website. Pada aplikasi web bagian view biasanya berupa file template HTML, yang diatur oleh controller. Bagian ini tidak memiliki akses langsung terhadap bagian model namu berhubungan langsung dengan controller. View berfungsi untuk menerima dan merepresentasikan data kepada pengguna. Jadi bisa di katakan bahwa viiew merupakan halaman web.

\section{Controller}

Controller merupakan bagian yang menjembatani model dan view. Controller berisi perintah-perintah yang berfungsi untuk memproses suatu data dan mengirimkannya ke halaman web. Controller berfungsi untuk menerima request dan data dari user kemudian menentukan apa yang akan diproses oleh aplikasi.

\section{II.6 Pengertian CSS}

CSS adalah singkatan dari Casading Style Sheet yang merupakan kumpulan perintah yang dibentuk dari berbagai sumber yang disusun menurut urutan tertentu sehingga mampu mengatasi konfik style. CSS atau yang disebut Cascading Style Sheet yaitu salah satu bahasa pemrograman web yang mengatur komponen dalam suatu web supaya lebih terstruktur dan lebih seragam.

\section{II.7 Pengertian Sublime Text Editor}

Sublime Text Editor adalah editor teks untuk berbagai bahasa pemograman termasuk pemograman PHP. Sublime Text Editor merupakan editor text lintas platform dengan Python Application Programming Interface (API). Sublime Text Editor juga mendukung banyak bahasa pemrograman dan bahasa markup, dan fungsinya dapat ditambah dengan plugin, dan Sublime Text Editor tanpa lisensi perangkat lunak.

\section{II.8 Metode Relational Unified Process (RUP)}

Relational Unified Process (RUP) adalah pendekatan perangkat lunak yang dilakukan berulangulang (iterative), fokus pada arsitektur (architecturecentric), lebih diarahkan berdasarkan penggunaan kasus (use case driven). RUP merupakan proses rekayasa perangkat lunak dengan pendefinisian yang lebih baik (well defined) dan penstrukturan yang baik (well structured). RUP menyediakan pendefinisian yang baik untuk alur hidup proyek perangkat lunak. RUP adalah sebuah produk proses perangkat lunak yang dikembangkan oleh Rational Software yang diakuisisi oleh IBM di bulan Febuaari 2003.

Proses pengulangan/iteratif pada RUP secara global dapat dlihat sebagai berikut:

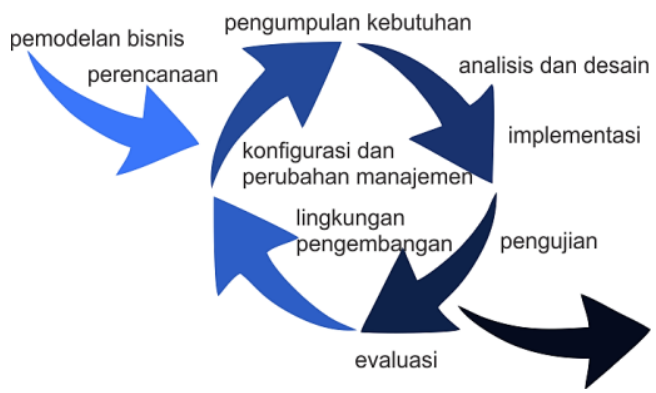

Gambar 3. Proses iteratif RUP

Menurut Menurut A.S Rosa dan M. Shalahudin, RUP memiliki 4 tahap atau fase yang dapat dilakukan pula secara iteratif. Berikut adalah penjelasan untuk setiap fase RUP (Rosa \& Shalahudin, 2013):

1. Inception (permulaan)

Tahap ini lebih pada memodelkan proses bisnis yang dibutuhkan (business modeling) dan mendefinisikan kebutuhan akan sistem yang akan dibuat (requirements).

2. Elaboration (perluasaan/perencanaan)

Tahap ini lebih difokuskan pada perencanaan arsitektur sistem. Tahap ini juga dapat mendeteksi apakah arsitektur sistem yang diinginkan dapat dibuat atau tidak. Mendeteksi resiko yang mungkin terjadi dari arsitektur yang dibuat. Tahap ini lebih pada analisis dan desain sistem serta implementasi sistem yang fokus pada purwarupa sistem (prototype).

3. Construction (konstruksi)

Tahap ini fokus pada pengembangan komponen dan fitur-fitur sistem. Tahapan ini lebih pada implementasi dan pengujian sistem yang fokus pada implementasi perangkat lunak pada kode program. Tahap ini menghasilkan produk perangkat lunak dimana menjadi syarat dari Initial Operational Capability Milestone atau batas/tonggak kemampuan operasional awal.

4. Transition (transisi)

Tahap ini lebih pada deployment atau instalasi sistem agar dapat dimengerti oleh user. Tahap ini

Johni S Pasaribu 
menghasilkan produk perangkat lunak dimana menjadi syarat dari Initial Operational Capability Milestone atau batas/tonggak kemampuan operasional awal. Aktifitas pada tahap ini termasuk pada pelatihan user, pemeliharaan dan pengujian sistem apakah sudah memenuhi harapan user.

\section{II.9 Penelitian Terkait}

Berdasarkan penelitian sejenis dari Pramitha Dita Syilvia dan Budi Yuwono (Syilvia \& Yuwono, 2012), yang berjudul Perancangan Sistem Informasi Penerimaan Siswa Baru di SMA 1 BAE Kudus Berbasis Intranet dijelaskan bahwa dalam era komputerisasi seperti ini dibutuhkan pelayanan yang cepat dalam segala bidang tidak terkecuali dalam hal penerimaan peserta didik baru. Agar mempercepat dalam penginputan maupun pengolahan data calon peserta didik baru, maka diperlukan sebuah aplikasi yang membantu mempermudah dalam pengolahan data. Dengan adanya sistem penerimaan peserta didik pada SMA 1 BAE Kudus ini diharapkan dapat mempermudah dalam penginputan dan dan pengolahan data serta pelaporannya. Sehingga dapat mempercepat proses pendaftaran dan meningkatkan pelayanan, sehingga waktu yang digunakan dapat lebih efektif. Akan tetapi sistem informasi ini tidak dapat memberikan kemudahan kepada calon siswa baru untuk mendapatkan informasi mengenai tata cara dan syarat pendaftaran sebagai siswa baru.

Pada tahun 2010, Sidiq Wahyu Surya Wijaya melakukan penelitian yang berjudul Sistem Informasi Penerimaan Mahasiswa Berbasis Web dan Wap (Wijaya, 2010). Permasalahan yang muncul sebelum sistem dibangun adalah calon mahasiswa masih banyak yang merasa kesulitan dengan sistem tersebut karena tidak adanya fitur konfirmasi pembayaran pendaftaran online. Tujuannya ialah merancang suatu sistem yang berfungsi untuk memberikan informasi penerimaan mahasiswa baru dan melakukan pendaftaran serta konfirmasi pembayaran pendaftaran online melalui Web dan Wap. Setelah sistem dibangun hasilnya adalah sistem informasi penerimaan mahasiswa baru berbasis Web dan Wap sudah memberikan kemudahan kepada calon mahasiswa dalam mengakses informasi dan melakukan proses pendaftaran serta konfirmasi pembayaran pendaftaran online. Akan tetapi sistem informasi ini tidak dapat menyediakan fasilitas cetak tanda bukti pendaftaran dalam format pdf.

Pada tahun 2012, Ayu Rindy Mutiara Suci melakukan penelitian yang berjudul Sistem Informasi
Pendaftaran Siswa Masuk Sekolah Online Pada SMAN 2 Pacitan (Suci, 2012). Permasalahan yang muncul sebelum sistem dibangun adalah penerapan metode pendaftaran tersebut masih kurang efektif dan efisien. Diantaranya adalah membutuhkan waktu yang lama untuk proses pendaftaran bagi calon siswa baru, kesulitan dalam mencari informasi seputar persyaratan dan pengumuman penerimaan siswa baru, hilang dan rusaknya dokumen. Tujuan dari sistem yang dibangun adalah menghasilkan sistem informasi pendaftaran siswa masuk sekolah online pada Sekolah Menengah Atas Negeri 2 Pacitan yang efektif dan efisien. Setelah sistem dibangun hasilnya adalah memberikan kemudahan untuk pihak SMA Negeri 2 Pacitan dalam proses penerimaan siswa dan memberikan kemudahan bagi calon siswa baru dalam proses pendaftaran sekolah. Akan tetapi sistem informasi ini tidak dapat memberikan kemudahan kepada calon siswa baru untuk menerima konfirmasi pembayaran pendaftaran secara online.

Pada jurnal tahun 2012 yang berjudul Sistem Informasi Penerimaan Siswa Baru Di SMK Bhina Tunas Bhakti Juwana Pati (Sukono, 2012), Sukono menjelaskan bahwa penerimaan siswa baru merupakan upaya instansi sekolah untuk memperoleh calon siswa baru yang sesuai dengan kriteria setiap sekolah, sehingga tahapan ini merupakan tahapan yang penting. Akan tetapi pengolahan data penerimaan siswa baru selama ini masih dilakukan secara konvensional (tanpa komputerisasi) sehingga terdapat berberapa kendala. Dengan adanya sistem informasi penerimaan siswa baru diharapkan dapat mengatasi permasalahan yang sering dihadapi dalam penerimaan siswa baru di SMK Bhina Tunas Bhakti Juwana. Akan tetapi sistem informasi ini tidak memberikan informasi tentang hasil seleksi siswa baru dengan cepat melalui internet.

Berdasarkan jurnal dan tinjauan penelitian terkait tersebut maka penulis akan melakukan penelitian serta perancangan yang sama yaitu mengenai sistem informasi penerimaan siswa baru di SMP BPPI Baleendah yang akan mencoba menyempurnakan kekurangan-kekurangan tersebut tadi di atas.

\section{AnAlisis Dan Perancangan}

Perangkat lunak yang akan dibuat adalah Penerimaan Peserta Didik Baru di SMP BPPI Baleendah. Adapun kebutuhan fungsional dan kebutuhan non-fungsional perangkat lunak tersebut seperti pada tabel 1 dan 2 . 
Tabel 1. Kebutuhan Fungsional

\begin{tabular}{|c|c|c|}
\hline No & $\begin{array}{l}\text { Kebutuhan } \\
\text { Fungsional }\end{array}$ & Yang dilakukan aktor \\
\hline 1 & $\begin{array}{l}\text { Sistem harus mampu } \\
\text { menerima } \\
\text { pendaftaran siswa } \\
\text { baru }\end{array}$ & $\begin{array}{l}\text { Siswa melihat info PPDB dan } \\
\text { melakukan pendaftaran }\end{array}$ \\
\hline 2 & $\begin{array}{l}\text { Sistem harus mampu } \\
\text { mengelola profile } \\
\text { siswa baru }\end{array}$ & $\begin{array}{l}\text { Siswa mengelola data siswa } \\
\text { dimana di dalamnya terdapat data } \\
\text { siswa, keterangan tempat tinggal } \\
\text { siswa, identitas jasmani, } \\
\text { keterangan tentang pendidikan } \\
\text { sebelumnya, keterangan } \\
\text { intelegensia dan kegemaran, } \\
\text { keterangan tentang orangtua, aksi } \\
\text { cetak formulir dan perbaharui } \\
\text { data. }\end{array}$ \\
\hline 3 & $\begin{array}{lr}\text { Sistem harus } & \text { mampu } \\
\text { mengupload } & \text { bukti } \\
\text { pembayaran } & \text { siswa } \\
\text { baru } & \end{array}$ & $\begin{array}{l}\text { Siswa mengupload bukti } \\
\text { pembayaran untuk pendaftaran } \\
\text { siswa baru }\end{array}$ \\
\hline 4 & $\begin{array}{lr}\text { Sistem harus } & \text { mampu } \\
\text { mengelola } & \text { bukti } \\
\text { pembayaran } & \text { siswa } \\
\text { baru } & \end{array}$ & $\begin{array}{l}\text { Admin mengelola informasi } \\
\text { dimana di dalamnya terdapat aksi } \\
\text { terima pembayaran, tolak } \\
\text { pembayaran, lihat transaksi, } \\
\text { manage transaksi, pembaharui } \\
\text { data, batal, tambah data, dan } \\
\text { daftar data transaksi. }\end{array}$ \\
\hline 5 & $\begin{array}{l}\text { Sistem harus mampu } \\
\text { mengelola daya } \\
\text { tampung siswa baru }\end{array}$ & $\begin{array}{l}\text { Admin mengelola daya tampung } \\
\text { dimana di dalamnya terdapat aksi } \\
\text { tambah, lihat, daftar, edit, hapus, } \\
\text { dan cari. }\end{array}$ \\
\hline 6 & $\begin{array}{l}\text { Sistem harus mampu } \\
\text { mengelola data } \\
\text { pengguna }\end{array}$ & $\begin{array}{l}\text { Admin mengelola data pengguna } \\
\text { dimana di dalamnya terdapat aksi } \\
\text { tambah, edit, hapus, dan cari }\end{array}$ \\
\hline 7 & $\begin{array}{l}\text { Sistem harus mampu } \\
\text { mengelola database } \\
\text { proses pendaftaran } \\
\text { siswa baru }\end{array}$ & $\begin{array}{l}\text { Admin mengelola backup } \\
\text { database dimana di dalamnya } \\
\text { terdapat aksi tambah, hapus, } \\
\text { download, dan restore }\end{array}$ \\
\hline 8 & $\begin{array}{l}\text { Sistem harus mampu } \\
\text { memberikan laporan } \\
\text { siswa baru }\end{array}$ & $\begin{array}{l}\text { Admin memberikan laporan siswa } \\
\text { baru }\end{array}$ \\
\hline
\end{tabular}

\section{III.1 Use Case Diagram}

Diagram use case digunakan untuk mengetahui fungsi-fungsi apa saja yang ada dalam sebuah sistem dan siapa saja yang berhak menggunakan fungsifungsi tersebut. Berikut ini berisikan use case diagram untuk sistem penerimaan peserta didik baru di SMP BPPI Baleendah. Diagram use case dapat dilihat pada gambar 4

\section{III.2 Class Diagram}

Class Diagram berisi gambaran struktur dan penjelasan class, paket dan objek serta hubungan satu sama lain seperti asosiasi, pewarisan dan lain-lain dalam sebuah sistem. Berikut ini berisikan class diagram untuk sistem penerimaan peserta didik baru di SMP BPPI Baleendah.

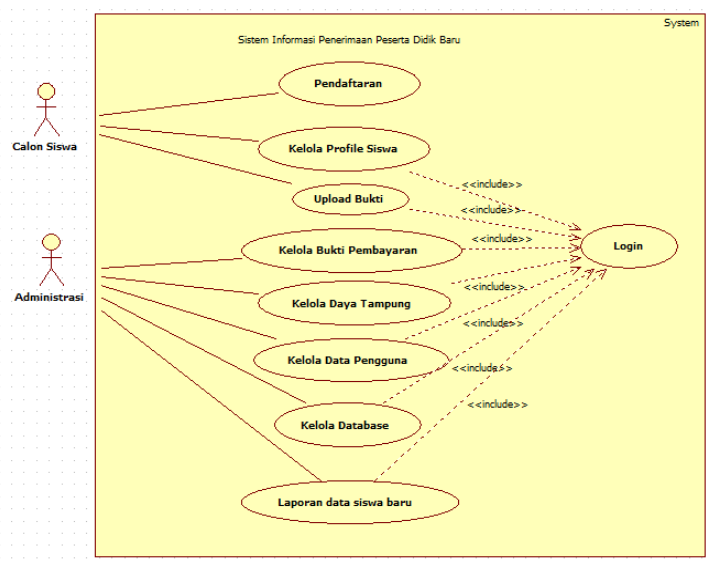

Gambar 4. Use Case Diagram PPDB di SMP BPPI Baleendah

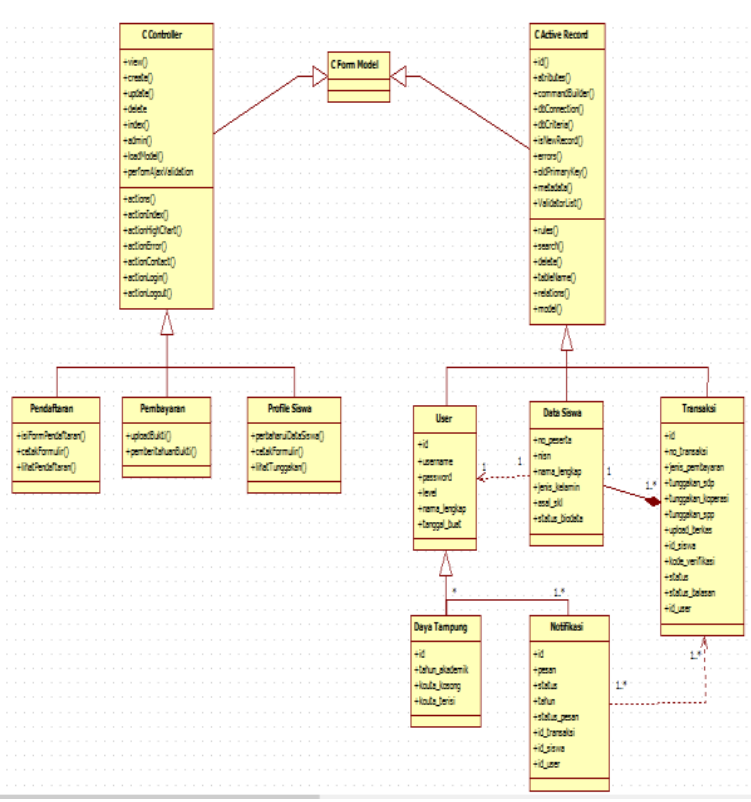

Gambar 5. Class Diagram Untuk Keseluruhan Sistem Model, View dan Controller

Class diagram untuk sistem Model yaitu kelaskelas: User, Data Siswa, Transaksi, Daya Tampung, Notifikasi, Pendaftaran, Pembayaran dan Profile Siswa. Sedangkan class diagram untuk sistem View adalah: C Active Record dan class diagram untuk sistem Controller adalah: C Controler dan C Form Model (bandingkan dengan gambar 2 sebelumnya).

Johni S Pasaribu 


\section{III.3 Activity Diagram}

Activity Diagram menggambarkan workflow (aliran kerja) atau aktivitas sebuah sistem atau proses bisnis. Gambar 6, 7 dan 8 menampilkan activity diagram untuk proses pendaftaran, upload bukti transaksi dan pengisian profil siswa pada PPDB.

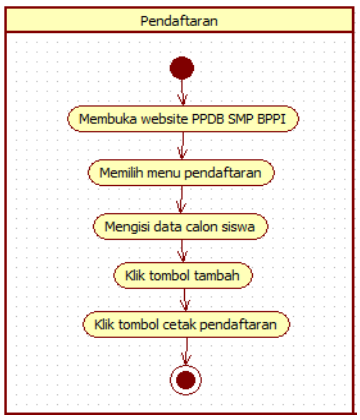

Gambar 6. Activity Diagram Proses Pendaftaran PPDB di SMP BPPI Baleendah

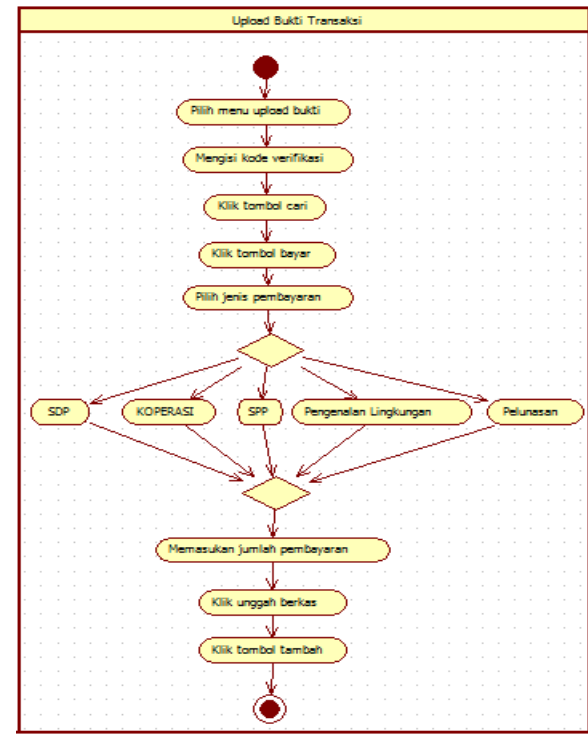

Gambar 7. Activity Diagram Proses Upload Bukti Transaksi PPDB di SMP BPPI Baleendah

\section{III.4 Perancangan Desain Basis Data}

Sub bab ini menjelaskan transformasi model data yang dihasilkan oleh proses analisis menjadi struktur data yang dibutuhkan pada saat implementasi. Gambar 9 menampilkan implementasi rancangan basis data yang akan digunakan pada aplikasi ini.

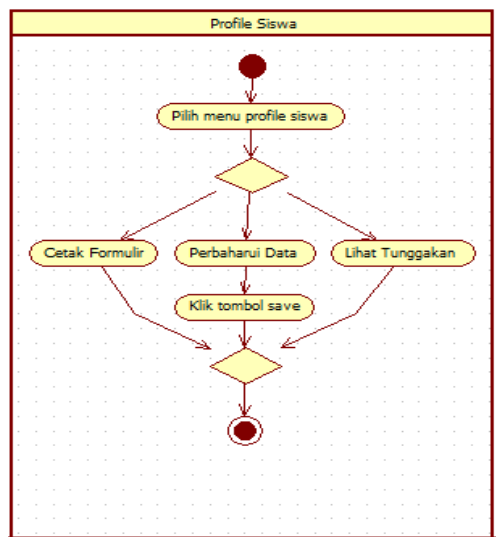

Gambar 8. Activity Diagram Proses Profile Siswa PPDB di SMP BPPI Baleendah

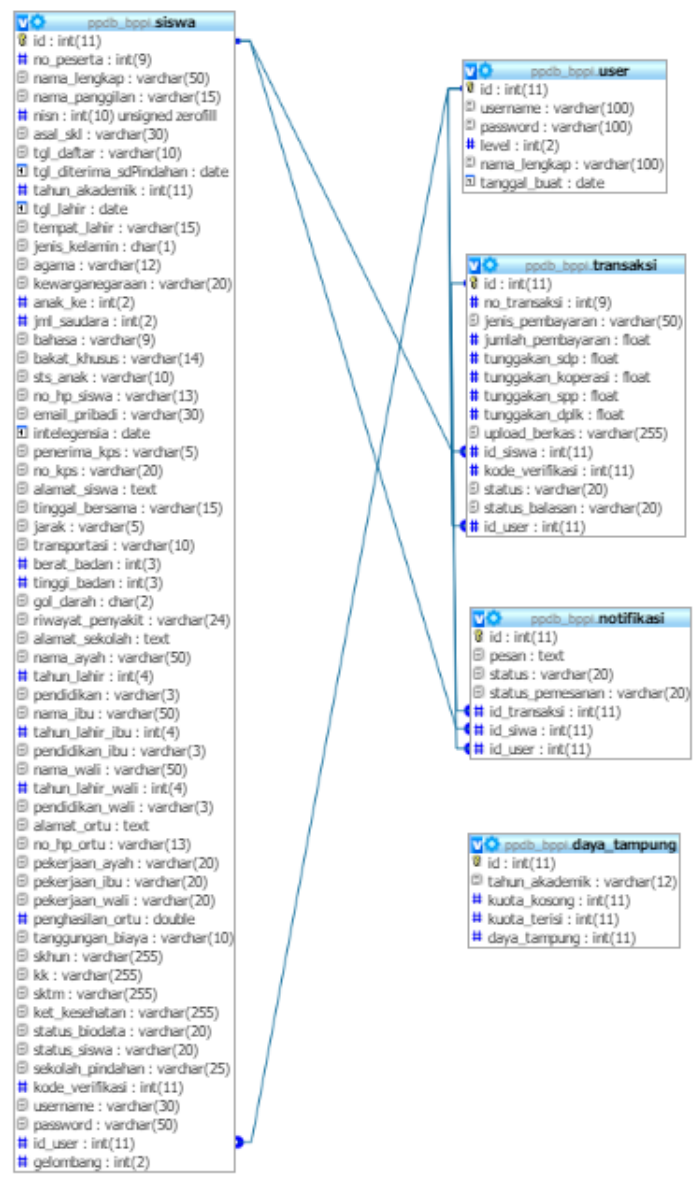

Gambar 9. Rancangan Basis Data 


\section{III.5 Implementasi Antar Muka}

Perancangan aplikasi memudahkan user dalam penggunaan sistem ini. Gambar 10 Dialog Screen Pendaftaran berfungsi agar calon siswa dapat mendaftarkan diri. Adapun uraiannya: buka aplikasi PPDB SMP BPPI, pilih menu pendaftaran, isi semua field yang sudah disediakan.

Dialog Screen Lihat Pendaftar berfungsi untuk melihat pendaftar. Adapun uraiannya: pilih menu Lihat Pendaftar, kemudian carilah nama calon siswa berdasarkan nama seperti pada Gambar11.

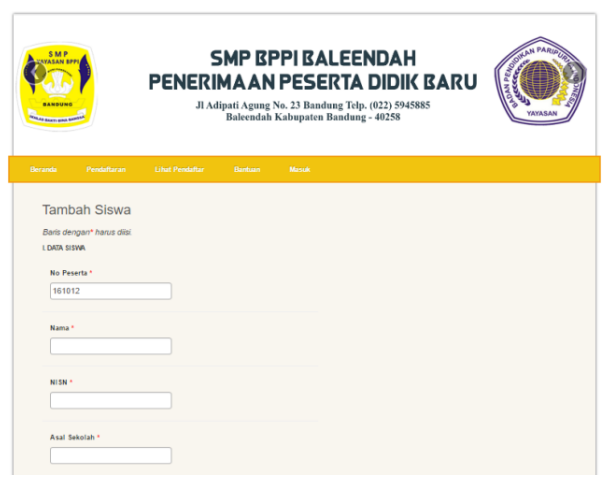

Gambar 10. Dialog Screen Pendaftaran

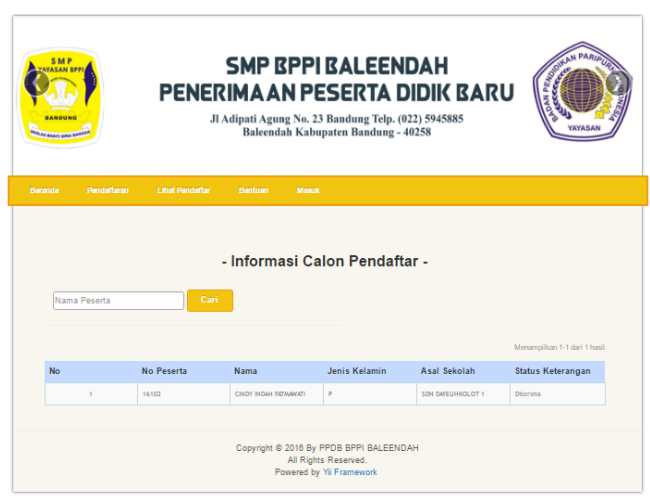

Gambar 11. Dialog Screen Lihat Pendaftar

Dialog Screen Bayar Transaksi berfungsi untuk melakukan pembayaran transaksi. Adapun uraiannya: pilih menu Upload Bukti Transaksi, kemudian unggah bukti transfer dari bank, klik tombol tambah maka akan tampil halaman transaksi seperti pada Gambar 12.

Dialog Screen Status Pendaftaran berfungsi untuk melihat status calon siswa. Adapun uraiannya: Pilih menu lihat pendaftar, kemudian carilah nama calon siswa berdasarkan nama seperti terlihat pada Gambar 13.

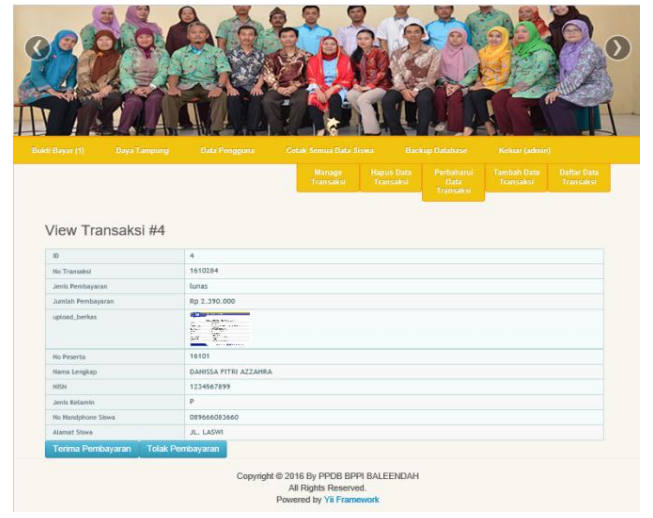

Gambar 12. Dialog Screen Bayar Transaksi

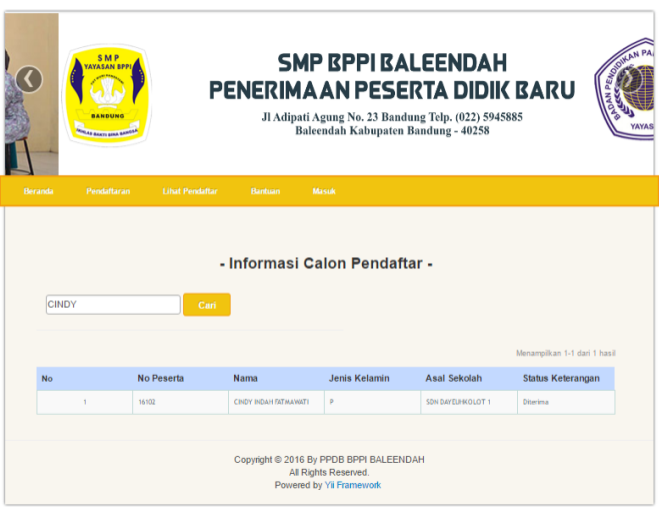

Gambar 13. Dialog Screen Status Pendaftaran

\section{KESIMPULAN DAN SARAN}

Berdasarkan analisa, implementasi dan pengujian yang telah dilakukan pada sistem informasi penerimaan peserta didik baru dengan penerapan pola desain MVC pada framework Yii, maka dapat ditarik kesimpulan sebagai berikut:

1. Dengan menggunakan framework Yii PHP dapat dibuat sebuah perangkat lunak aplikasi web sistem informasi untuk membantu penerimaan peserta didik baru. Dalam penelitian ini, perangkat lunak dikembangkan untuk membantu siswa dalam mengetahui hasil seleksi siswa baru dengan cepat melalui internet dan melakukan pembayaran pendaftaran siswa baru dengan cepat dan aman.

2. Adanya perangkat lunak ini dapat mempermudah segala proses PPDB mulai dari pendaftaran siswa sampai pengumuman hasil seleksi. 
3. Perangkat lunak ini dapat mempermudah dalam pengolahan data dan pencarian data bagi panitia PPDB.

4. Terdapat fasilitas login yang membatasi hak akses pengguna, sehingga akan meminimalisir manipulasi laporan oleh pihak yang tidak bertanggungjawab.

5. Membentuk sikap kemandirian calon siswa untuk mendapatkan informasi PPDB tanpa tergantung pada pihak sekolah SMP.

6. Dengan diterapkannya program Perangkat Lunak ini dapat mengurangi beberapa kendala yang masih menjadi gangguan dalam menyimpan data dan menampilkan kembali dalam bentuk informasi di bagian kearsipan serta menangani proses pendaftaran, informasi seleksi, dan informasi penerimaan.

Adapun untuk pengembangan lebih lanjut disarankan agar perangkat lunak yang sudah dibuat ini dikembangkan sehingga dapat terhubung langsung ke website SMP BPPI Baleendah agar dapat mempermudah calon siswa baru untuk melakukan proses pendaftaran.

\section{REFERENSI}

Supaartagorn, C. (2011). PHP Framework For Database Management Based On MVC Pattern. International Journal of Computer Science \& Information Technology (IJCSIT) Vol 3 No 2, 251-258.

Avensano, L., Canfora, G., De Lucia, A., \& Stefanucci, S. (2002). Understanding SQL Through Iconic Interfaces. Computer Software and Applications Conference (COMPSAC), (pp. 703-708).

Paikens, A., \& Arnicans, G. (2008). Use of Design Patterns in PHP-Based Web Application Frameworks. Department of Computing University of Latvia.

Upton, D. (2007). CodeIgniter for Rapid PHP Application Development. Birmingham: Packt Publishing.

DocForge. (2010). Web Application Framework. Retrieved from http://docforge.com/wiki/Web_application_f ramework

Yicheng, L. (2011). Development of a Blog System Using CodeIgniter Framework. Finland: Oulu University of Applied Sciences.
Shan, T. C., \& Hua, W. W. (2006). Taxonomy of Java Web Applications Frameworks. IEEE International Conference on e-Business Engineering (ICEBE'06).

Buschmann, F. (1996). Pattern-Oriented Software Architecture: A System of Patterns. 123-168.

Leff, A., \& Rayfield, J. T. (2001). Web-Application Development Using the Model/View/Controller Design Pattern. Enterprise Distributed Object Computing Conference, 2001. EDOC '01. Proceedings. Fifth IEEE International, (pp. 118-127). Seattle, WA.

Krasner, G. E., \& Pope, S. T. (1988). A Cookbook for Using the Model-View-Controller UserInterface Paradigm in Smalltalk-80. Journal of Object-Oriented Programming (pp. 2649). SIGS Publication.

Coutaz, J. (1987). PAC, An Object-Oriented Model for Dialog Design. Proceedings of HumanComputer Interaction (INTERACT) (pp. 431436). Elsevier Science Publishers.

Hofmeister, C., Nord, R. L., \& Soni, D. (2000). Applied Software Architecture. AddionWesley.

Sharive. (2013). YII Framework Menguasai PHP Terbaik. Yogyakarta: Lokomedia.

http://www.yiiframework.com/doc/guide/1.1/id/basics .mvc

Shalahuddin, M \& Rossa, A.S. (2013). Rekayasa Perangkat Lunak Terstruktur dan Berorientasi Objek. Bandung: Informatika.

Syilvia, P. D., Yuwono, B. (2012). Perancangan Sistem Informasi Penerimaan Siswa Baru di SMA 1 BAE Kudus Berbasis Intranet. Seruni FTI UNSA, Volume 1, ISSN: 2302-1136 (Print) - 2088-0154 (Online).

Wijaya, S. W. S. (2010). Sistem Informasi Penerimaan Mahasiswa Baru Berbasis WEB dan WAP. Jurnal Speed Vol 7 No 2 Agustus 2010 ISSN : 1979-9330 (Print).

Suci, A. R. M., Purnama, B. E. (2012). Sistem Informasi Pendaftaran Masuk Sekolah Online pada Sekolah Menengah Atas Negeri 2 Pacitan. Jurnal Speed Vol 9 No 2 Agustus 2012 ISSN : 1979-9330 (Print).

Sukono. (2012). Sistem Informasi Penerimaan Siswa Baru Di SMK Bhina Tunas Bhakti Juwana Pati. Jurnal Seruni FTI UNSA, Volume 1, ISSN: 2302-1136 (Print) - 2088-0154 (Online). 